Check for updates

Wolfson Institute of Population Health, Barts and The London Schoo of Medicine \& Dentistry, Queen Mary University of London, UK

2 The George Institute for Global Health at Peking University Health Science Center, China.

3 Faculty of Medicine, University of New South Wales, Australia

Cite this as: $B M J 2022 ; 376: 0381$ http://dx.doi.org/10.1136/bmj.0381 Published: 14 February 2022

\section{Can children play a role in reducing families' salt intake?}

\author{
Feng J He, ${ }^{1}$ Puhong Zhang, ${ }^{2,3}$ Yuan Li, ${ }^{2,3}$ Graham A MacGregor ${ }^{1}$
}

There is robust evidence that a reduction in salt intake lowers blood pressure and reduces the risk of strokes, heart attacks, and heart failure. ${ }^{1}$ But how can population wide salt consumption be reduced effectively? Several developed countries have been successful in reducing their populations' salt intake mainly by setting incrementally lower salt targets for processed foods, which account for approximately $70-80 \%$ of salt intake. ${ }^{2}$ Developing countries, however, are lagging behind. China is the largest developing country with a population of 1.4 billion. Salt intake in China is very high, with an average intake per person of more than double the World Health Organisation's (WHO) recommended maximum. ${ }^{3}$ Unlike developed countries, in China approximately $80 \%$ salt is added during cooking at home. It is very difficult to reduce salt intake in these settings as it is challenging to change individuals' dietary behaviours.

A few years ago, we tried a different approach-educating primary schoolchildren during their usual health education lessons about the risks of eating too much salt and how to reduce it. Children's homework was to deliver the message to the whole family and persuade the people who did the cooking to reduce the amount of salt used. A study in northern China showed that a school based programme is effective in lowering salt intake by around $25 \%$ in children and their families for about 3.5 months. ${ }^{4}$ But a more innovative approach would be needed to sustain lower salt intake for long term.

In a new study, published in The BMJ, we developed an app-based programme to provide salt reduction education in place of in-school teaching. Children and their families can use the app to learn about reducing salt. They can also use the app to estimate their salt intake, set salt reduction targets, and monitor progress by themselves. ${ }^{5}$ The app was installed on parents' smartphones, but the programme was delivered through primary schools. Children's homework was to get the whole family involved in the salt reduction activities following the guide in the app. The study involving 54 primary schools in northern, central, and southern China and demonstrates that this app-based education programme is feasible and effective in lowering the families' salt intake over one year. ${ }^{6}$ Importantly, the programme was accepted and perceived as an engaging education tool by most participants and teachers.

However, the online learning was challenging for a small number of the children because they lived with their grandparents who did not have a smartphone. In such cases, we provided online salt reduction courses for teachers to use in the classroom, so that these children could still receive the information and follow the instructions to get their families to reduce salt.

The app-based education programme could potentially be scaled up across China. Our intervention strategy could also possibly be adapted by other countries, particularly in the settings where most of the salt intake in the diet is added by people in their home cooking.

The education model which we developed and tested in our study, including the use of m-Health technology and a "child-to-parent" approach, could potentially be adapted for other dietary and lifestyle changes, e.g. reducing sugar and saturated fat intake and increasing fruit and vegetable consumption.

Competing interests: FJH is an unpaid member of Action on Salt and World Action on Salt, Sugar and Health (WASSH). GAM is the unpaid Chairman of Blood Pressure UK, Chairman of Action on Salt and Chairman of WASSH. Other authors declare no competing interests.

Provenance and peer review: commissioned, not peer reviewed

He FJ. Tan M. Ma Y, MacGregor GA. Salt Reduction to Prevent Hypertension and Cardiovascular Disease: JACC State-of-the-Art Review. J Am Coll Cardiol 2020;75:632-47. doi: 10.1016/j.jacc.2019.11.055 pmid: 32057379

2 He FJ, Pombo-Rodrigues S, Macgregor GA. Salt reduction in England from 2003 to 2011: its relationship to blood pressure, stroke and ischaemic heart disease mortality. BMJ Open 2014;4:e004549. doi: 10.1136/bmjopen-2013-004549 pmid: 24732242

3 Li Y, Zhang P, Wu J, etal. Twenty-Four-Hour Urinary Sodium and Potassium Excretion and Their Associations With Blood Pressure Among Adults in China: Baseline Survey of Action on Salt China. Hypertension 2020;76:1580-8.

doi: 10.1161/HYPERTENSIONAHA.120.15238 pmid: 32981359

4 He FJ, Wu Y, Feng XX, etal. School based education programme to reduce salt intake in children and their families (School-EduSalt): cluster randomised controlled trial. BM/2015;350:h770. doi: 10.1136/bmj.h770 pmid: 25788018

5 He FJ, Zhang P, Luo R, etal. An Application-based programme to reinforce and maintain lower salt intake (AppSalt) in schoolchildren and their families in China. BMJ Open 2019;9:e027793. doi: 10.1136/bmjopen-2018-027793 pmid: 31272977

6 He FJ, Zhang P, Luo R, etal. App based education programme to reduce salt intake (AppSalt) in schoolchildren and their families in China: parallel, cluster randomised controlled trial. BM/2022·376:e066982. doi: 10.1136/bmj-2021-066982 pmid: 35140061 